\title{
Inhaltswerzeidnnis.
}

Cinleitung.

Stite

\section{Augenetuer Tetl.}

I. Abjønitt. Ban nem Yeruehmenden . ". . . . . . . . . . . 1

1. Allgemeines . . . . . . . . . . . . . . . . . . 1

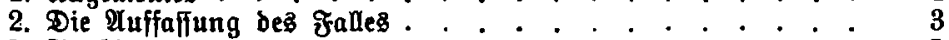

3. Sonftigeb . . . . . . . . . . . . . . . . . . 5

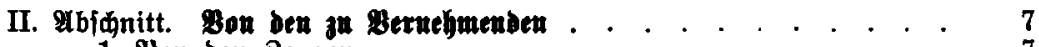

1. Bon ben Beugen . . . . . . . . . . . . . . 7

a) Wenn ber Beuge die Wahrheit nidt fagen tann . . . 8

2. Bon ben Béfqulb"igten" . . ". . . . . . . . . . . . . . 14

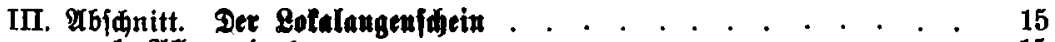

1. 2 Ulgemetnez . . . . . . . . . . . . . . . . . . 15

2. $\mathfrak{A}$ uffuhen von Berborgenem . . . . . . . . . . . . . 20

IV. abfinnitt. Heber ben Sabuerftänbigen . . . . . . . . . . . 22

1. $\mathfrak{a}$ gemeines . . . . . . . . . . . . . . . . . 22

2. Die Beriftäräzte . . . . . . . . . . . . . . . . 22

3. Die Mitroftopiter . . . . . . . . . . . . . . . . 24

a) Bei Blutipuren . . . . . . . . . . . . . . . . 24

b) Extrementen . . . . . . . . . . . . . . . 24

c) "Saaren . . . . . . . . . . . . . . . . . 25

d) " Şariftfäliðügen : . . . . . . . . . . . . . 26



f) Ünterfucung von Berunreintgungen . . . . . . . . . . . 27

4. Die Chemiler . . . . . . . . . . . . . . . 28



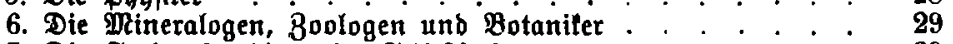

7. Die Sadverftändigen im Sđießfade . . . . . . . . . . . . 29

8. Der ßgotograph . . . . . . . . . . . . . . . . 30

V. Rlbjănitt. Canuerpraltilen . . . . . . . . . . . . . . . 31

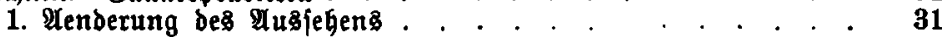

2. Falfide Ramen . . . . . . . . . . . . . . . . $\mathbf{3 3}$

3. Simulation bon Sranlgeiten und Seiben . . . . . . . $\quad 37$

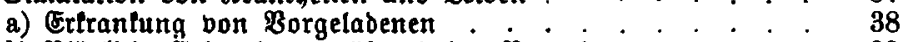

b) \$lößlide Ertrantung mährend ber Bernebmung . . . . 38

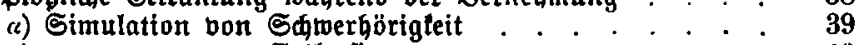

B) " "Epilepfie . . . . . . . 40

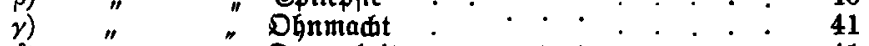

d) " "Dummbeit . . . . . . . . . . . 41

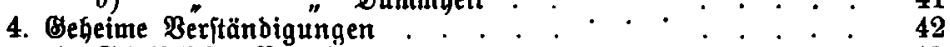

A. Ş九riftliळer Berfehr . . . . . . . . . . . . . 42

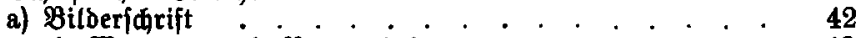

1. Wappen= und Ramenzititen . . . . . . . . . . , $4 \mathbf{4 2}$

a) allgemeine . . . . . . . . . . . . . . . . . . . . . . $\quad 49$

b) bejondere . . . . . . . . . . . . . 43

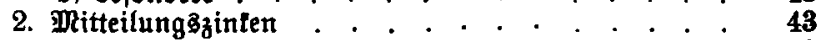

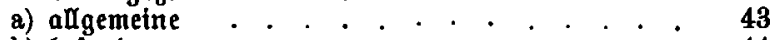

b) befondere. . . . . . . . . . . . . . . . . . . . . 44

3. Lotale Bezeidnungen . . . . . . . . . . . . . 44 
b) Beheimidriften

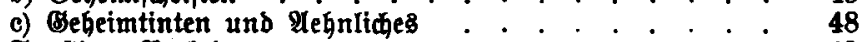

B. Sonjtiger Berlehr

a) Jaozinfen . . . . . . . . . . . . . . . . . . . . . . 49

b) \ennginten . . . . . . . . . . . . . . . . 50

c) Sautginten . . . . . . . . . . . . . . . . . . . . 5

a) \&od= und

B) Berlehr in ben Befängnifien : . . . . . . 52

d) Bigeunerzeiden . . . . . . . . . . . . . . 53

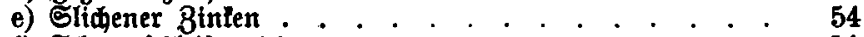

f) Sderenidleiferzeiden . . . . . . . . . . . . . . 54

C. Baunerjprade . . . . . . . . . . . . . . . 54

VI. झbjßnitt. Die Bigenuet . . . . . . . . . . . . . . . 56



2. Då Stehlen der Bigeuner. . . . . . . . . . . . . 58

3. Minderdiebftahl . . . . . . . . . . . . . . . . 61

4. Bute Eigenjăaten und ßeligion : . . . . . . . . . . . 61

5. Diebsిwerfyeuge und Bift . . . . . . . . . . . . . . . 61



7. 尺amen ber Bigeuner. . . . . . . . . . . . . . . . . . 63



VII. Abfdnitt. Der Mberglauben . . . . . . . . 64

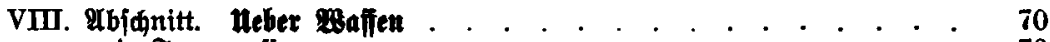

A. ऊeuerwaffen . . . . . . . . . . . . , . . . . 70

I. $\mathfrak{A}$ glgemeines

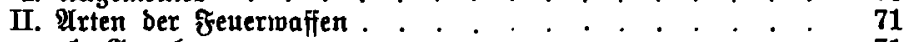

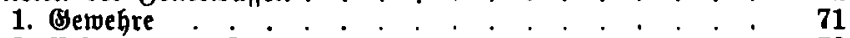



3. Rebolber . . . . . . . . . . . . . . . . 79

B. §ieb= unb Stiqwaffer . . . . . . . . . . . . . 81

IX. Abiønitt. Heber Spuren . . . . . . . . . . . . . . . 82

A. Fuspureı . . . . . . . . . . . . . . . . . . 82

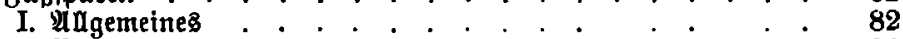

II. Bejondcreş . . . . . . . . . . . . . . . . . . . . . . . 84

A) Mugemeine Erjidetnungsformen . . . . . . . . . . 84

1. Belleibung . . . . . . . . . . . . . . 84

2. Entftehunģat . . . . . . . . . . . . . . . . 85



4. Bangart . . . . . . . . . . . . . $\quad .87$

5. Irittart . . . . . . . . . . . . 88



B) Bejonbere Erimeinung gformen . . . . . . . . . . . . . 90

1. (Gröpen . . . . . . . . . . . . . . . 90

В. Blutipuren

1. Das Muffucjen .

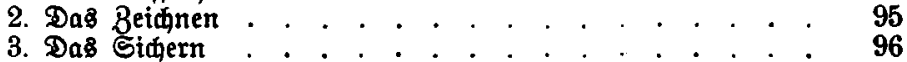



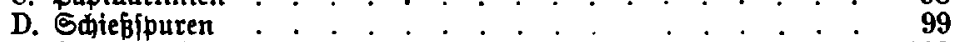

E. Sonftige Spuren . . . . . . . . . . . . . . . . 102

X. 9lbínnitt. Beidutu und Berwaubtes . . . . . . . . . . 104

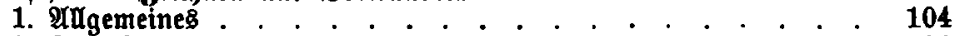

2. Dą Beidnen . . . . . . . . . . . . . . . . . 106

A. Efizzieren eines łnnentaumes . . . . . . . . . . . . . 109





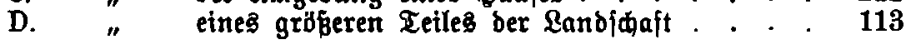


Gette

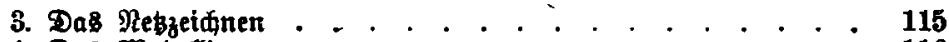

4. Dab Modellieren . . . . . . . . . . . 116

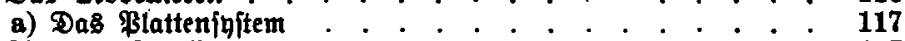

b) " Ragelinftem . . . . . . . . . . . . . . . . 117

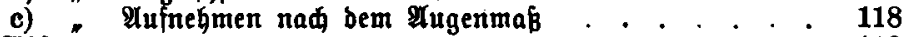

5. Ebformen , . . . . . . . . . . . . . . . . 118

6. घbllatiden . . . . . . . . . . . . . . . . . 119

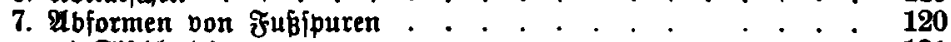

a) Eijhlerleim . . . . . . . . . . . . . . . . . . . : 121

b) Stearin . . . . . . . . . . . . . . . . . . 121

c) Bips . . . . . . . . . . . . . . . . . . 121

d) Bement . . . . . . . . . . . . . . . . . . 123

e) Sdpmejel . . . . . . . . . . . . . . . . . . . . . . 123



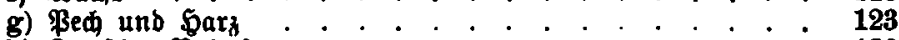

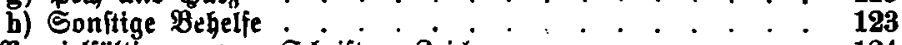

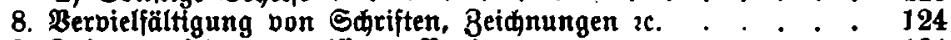

9. Bujammenjebung zerriffener ßapiere .......... . 124

10. Bertobltę \$apier . . . . . . . . . . . . . . . . 126

\section{Befonberex Tetl.}





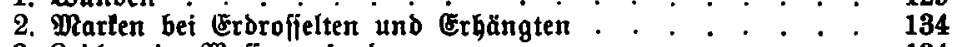

3. Qeiden im $\mathfrak{B a f i j e r ~ g e f u n d e n ~ . ~ . ~ . ~ . ~ . ~ . ~ . ~ . ~ . ~ . ~ . ~ . ~} 134$

4. Bergiftungen

5. Abtreibung der Leibesfrudt

6. Selbitmord

XII. Ubidnitt. Diebftabl . . . . . . . . . . . . . . . . 143

A. थ̈gemeines . . . . . . . . . . . . . . . . . . . 143

B. Bejonderes . . . . . . . . . . . . . . . . . . 143

1. Austunbjaften . . . . . . . . . . . . . . . 143

2. Sonjtige Borbereitungen . . . . . . . . . . . . . 145



4. Gehilfen . . . . . . . . . . . . . . . . . 147

a) Aufpaffer

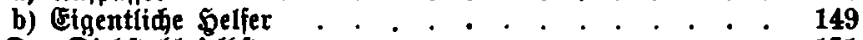

5: Der Diebitahl jelbft. . . . . . . . . . . . . 151

a) Einbrubbiebftahl . . . . . . . . . . . . . . . . . .

b) Rajфiendiebjtahl . . . . . . . . . . . . . . . 158

c) Der Cinjulleidbieb . . . . . . . . . . . . . . . . . 160

d) Martt= und Labendiebftahl . . . . . . . . . . 160

e) Fausbiebjtahl . . . . . . . . . . . . . . . . 162

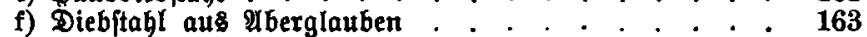

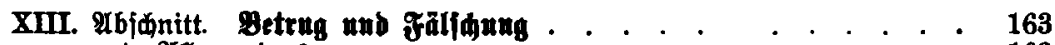



B. Urtundenfäliqung : . . . . . . . . . . . . . . . . . 164



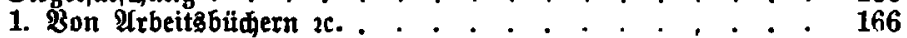



D. Betrug beim \$ferdehandel . . . . . . . . . . . . . . . 169

E. Spielbetrug . . . . . . . . . . . . . . . . . . 173

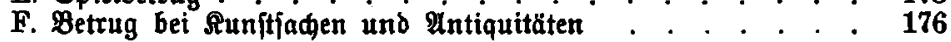



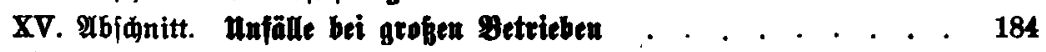

Megifter . . . . . . . . . . . . . . . . . . . . . . 187 
